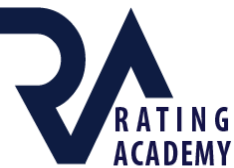

\title{
Journal of Arts
}

Cilt / Volume 2, Sayı / Issue 3, 2019, pp. 151-168

E - ISSN: 2636-7718

URL: https://ratingacademy.com.tr/ojs/index.php/arts/index

DOİ: https://doi.org/10.31566/arts.2.011

Araştırma Makalesi / Research Article

\section{HAYALET ORKİDE-MANTAR ve TEKNOLOJİ-SANAT İLISSKISİ}

\section{GHOST ORCHID-FUNGUS AND TECHNOLOGY-ART RELATIONSHIP}

\author{
Osman TÖRER * \\ * Mimar Sinan Güzel Sanatlar Üniversitesi, TÜRKIYE, E-mail: osmantorer78@gmail.com \\ ORCID ID: https://orcid.org/0000-0003-4588-8704
}

Geliş Tarihi: 8 Temmuz 2019; Kabul Tarihi: 29 Temmuz 2019

Received: 8 July 2019; Accepted: 29 July 2019

\section{$\ddot{O Z Z E T}$}

Sanat ve teknoloji birbirinden ayrllmaz bir bütündür. Mağara döneminden günümüze teknolojiyi bir araç olarak sanat alanında kullanmaktayız. Görsel ve estetik ihtiyaçların vazgeçilmezi olan teknolojinin sanat tarihi içerisindeki yeri bellidir. Sanatın kendini sürdürebilmesi için çağın getirdiği yenilikleri takip etmesi gerekliliği vurgulanmıştır. Pek çok sanatçı makine ile dolaylı olarak bağ kurmaktadır. Bu birliktelik ister klasik sanat ister modern sanat anlamında olsun üretilen eserlerde kendini göstermektedir. Sanat, teknolojinin takipçisidir. Bu görüşlerden hareketle makalenin temel izleği sanat ile hayalet orkide arasında kurulan benzerliktir. Sanat, var olması için gereken şartları teknolojiyle sağlayabileceği bir çiçek çerçevesinde tartışılmaktadır

Anahtar Kelimeler: Makine, Orkide, Sanat, Sibernetik, Teknoloji,

\section{ABSTRACT}

Art and technology are inseparable from each other. We use technology as a tool in the field of art from the cave period to the present. The place of technology, which is indispensable for visual and aesthetic needs, is stated in the art history. In order to sustain of art itself, the necessity of following the innovations brought by the ages has been emphasized. Many artists connect with the machine indirectly. This bond manifests itself in works that produced, whether in the sense of classical art or modern art. Art is a follower of technology. Based on these views, the main follow-up of the article is the similarity established between art and Ghost Orchids. Art is discussed within the framework of a flower in which it can provide the necessary conditions for its existence with technology

Keywords: Art, Cybernetics, Machine, Orchid, Technology, 


\section{GİRIŞ}

Latince adı Epipogium Aphyllum olan orkide, Avrupa, Kuzey Asya, İspanya ve Güney Himalaya bölgelerinde görülen nadir bir bitkidir. (Graham, 1953, 33) Kimilerine göre de soyu tükenmiştir. Bu çiçeğin nadir görülmesinin hatta soyu tükenmiş bitki sınıfına girmesini nedeni bitkinin yapraklarının olmayışıdır. Yaprakları olmadığı için fotosentez yapamaz ve kendi besinini üretemez. Toprak altında y1llarca yaşayabilir. Uygun koşul bulduğunda çiçek açmaktadır. Bu yaşam koşulları için başka bir değişle çiçeğin tekrar canlanması için bir mantara ihtiyacı vardır. Mantar, hayalet orkidenin tüm yaşamsal ihtiyaçlarını karşılamaktadır. Mantar ve hayalet orkide birbirlerini besler ve büyütür. Bitkiler arası bağ birbirinin yaşam döngüsünü etkileyecek şekildedir. Mantar ve orkide arasındaki ilişki sanat ve teknolojiyle benzetilebilir. Teknolojinin gelişimi sanatın devamlılığını getirir. İlk çağ döneminden uzay çağına uzanan insanlık tarihinde makine ve sanat bilinci beraber yol almıştır. Her yeni teknoloji bir öncekinin yerini almaktadır. Her üretilen sanat yapıtı bir önceki teknolojinin ürünlerini kullanmaktadır. İcat edilen teknoloji uygulanabilirliği bakımından önce denenir daha sonra sanatçının tezgahına gelir. Sanatçı o teknolojiyi kendi sanat dilinde bir şekle sokar ve izleyene sunar.

"Sanat daha ilk günden itibaren teknolojiden etkileniyordu. Lascaux Mağarası'nın duvarlarındaki resimler o günün teknolojisinin de bir yansımasıyd. Teknoloji insanın eli demekteydi. Nitekim 40 bin yı öncesinden gelen mağara duvarlarına insanın eli izini bırakması teknoloji ve sanatı üreten insanın en büyük gerçeğiydi. İnsan, işaret ve baş parmağını birleştirerek kendi kaderini yaratmaya başlamıştı ve bu, teknoloji ve sanat demekti." (Shanken, 2012:11)

Hayalet orkide ve sanat ilişkisi kendini sürekli yenileyen teknolojiyle mantar arasında ayrılmaz bir bütünün parçalarıdır. 19. yüzyılın bitki keşfi olan hayalet orkide sanayi devrimiyle yeri göğü inleten, buharıyla adeta gizemli bir sahne oluşturan makinelerin sanatla olan ilişkisine simgesel bir ayna vazifesi görmüştür. Techne, Antik Yunan kültüründe hem zanaati hem de sanat objesini ifade ettiği için, söz konusu dönemde muhteşem bir zırh için de, güzel bir biçimde yapılmış bir heykel için de, bir kap için de kullanılabilmekteydi. Aslında techne "Bilgi" demektir. Sanat ve teknik beceri ile yaratıcı ve üretici bilgidir. (Heidegger,2017:59)

Resim 1. Hayalet Orkide Orman İçinde Görünümü

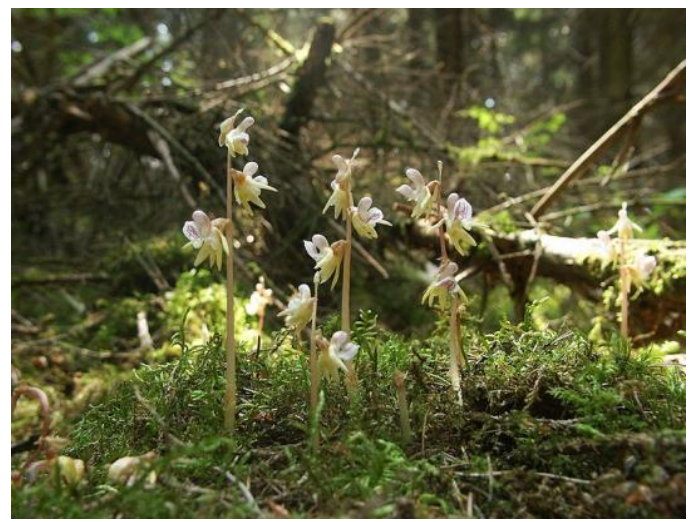

Kaynak: https://www.first-nature.com/flowers/epipogium-aphyllum.php 
Resim 2. Hayalet Orkide ve Mantar Görünümü.

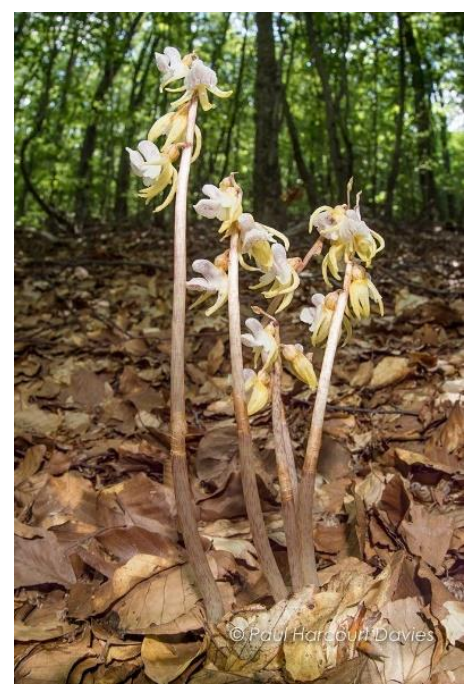

Kaynak: https://www.first-nature.com/flowers/epipogium-aphyllum.php

\section{SANAT VE TEKNOLOJİ BİRLIKKTELİĞi}

\subsection{Techne ve Sanat}

Technenin standart Latince çevirisinin "ars" olduğunu görürüz. Bu çeviri günümüz Latin kökenli dillerde art olarak karşılanmıştır. Türkçeye sanat olarak çevrilen bu sözcük teknik beceri anlamına da gelmektedir. Sanat veya teknik beceri dediğimiz bu sözcük, techne olarak adlandırılan yaratıcı ve üretici bilgiyi oluşturan isimdir. Aristoteles, technenin bilinen ilk felsefi tanımını yapar.

"Bir techne yapmayla ilgili akli bir niteliktir. O aklı gerçekliğe uygun kullanır. Ruhun hakikate ulaştığı beş yol; Techne, ilmi bilgi, basiret, bilgelik, akıl var" demiştir. (Heidegger, 2017: 60) Aristoteles'e göre, bir şeyi en iyi nasıl yapacağını bilmeye karşıllı gelir. Techneyi eyleme değil de yaratmaya yönelik bir iyelik olarak tanımlar. Hedefi bir şey ortaya çıkarma olan, yaratma ve doğru bir plana göre yöneltilmiş technenin, insanın yarattığ araçlarla kendisini yücelten ve ölümsüzleştiren yaratıcı yeteneği teknoloji ile ilişkisi nedir? İnsanın maddi çevresini denetlemek ve değiştirmek amacıyla geliştirdiği araç gereçlerle bunlara ilişkin bilgilerin tümüdür. Teknoloji için techneyi kullanan insan, icat ettiği aletlere ustalıkla idare etmek yerine onun düşmanına dönüştüğü bir şey olursa? Malzemelerin, aletlerin ve yapısal düzeneklerin üretimi ve kullanımı tam anlamıyla teknolojinin kendisidir. Malzemeler arasında bir hiyerarşi mevcuttur diyemeyiz. Çünkü bir tornavidanın yaptığını bir pense yapamaz, bir kaynak makinesinin yaptığını çekiç yapamaz. Tüm parçalar birbirleriyle iletişim halindedir. Teknoloji ilerlerken 19. yy'dan kalma bir tornavidayla 21. yy'da kullandığımız tornavida aynı yapısal özelliklere sahiptir. İkisi de vida sıkmak veya sökmek için kullanılır. Fakat yapıldığı malzeme olarak birisi demir diğeri titanyum ya da karbon fiber malzeme olabilir. Yeni teknolojiler malzemelerin çeşitliliğini çoğaltırken kullanım amaçlarının aynı olmasını değiştirmez. Techne ve ars ile mantar ve orkide arasında mecazi anlamda benzerlik gösterir. Techne bir mantar vazifezi görerek içinde bulunduğu orkideyi yani ars (sanat)1 beslemektedir. $\mathrm{Bu}$ bir çıkar ilişkisi değildir. Karşılıklı alış-veriştir. Teknikle estetik duyguların alışverişidir.

Sanatın teknolojiye merhaba deyişi mağara dönemine rastlar. Kullanılan alet ve gereçler resmedilen duvarlarda, süs eşyalarında, gündelik eşyalarda kendini gösterir. Teknoloji ilerledikçe sanat kendini yenilemiştir. Tekniğin bir adım öteye taşınması sanatı da yerinde saymaktan kurtarmıştır. Antik Yunan'da sanatın kendisi technedir. Techne bir yapma süreci olarak tanımlanabilir Günümüz Latin kökenli dillerde bu "art" yani sanat olarak gelmiştir ve 
sanat veya teknik beceri olarak da çevrilebilmektedir. Aslında teknoloji, sanat ve bilgi anlamına da gelmektedir. (Heidegger,2017,13) Çünkü her araç-gereç gibi tekniğin de ne ve nasıl olacağını insan belirlemektedir. Teknolojinin ürünlerinden olan makine gereksinimlere göre şekil almaktadır. Makine teriminin anlamı 13.yüzyıldan itibaren teknik, mekanik ve görünüşüyle sınırlandırılmıştır. Ancak 17.yy'da tam anlamıyla makine terimi kullanılmaya başlamıştır. Makine ve techne sanatı oluşturan öğelerdendir. İnsan burada techneyi ve makineyi kullanarak sanat üretmeyi hedefler. Bu anlamda Endüstri çağı da Batı kültüründe tekniğin gelişmesiyle varılan bir aşamadır. Buhar ve elektrik gücünün kullanılmasıyla başlayan teknik, atom fiziği ve uzay çalışmaları sosyal yapının gelişmesiyle devam etmiştir. (Ípşiroğlu, 2009:13) Fabrikasyon ürünler, hızlı tüketim ve hızlı üretim kent kültürüyle sanat anlayışını değiştirmiştir.

Peki, sanat teknolojiden nasıl yararlanır? Ya da orkideyi besleyerek gelişmesine yardım eden mantarın görevi nedir? Techne'nin sanat olabilmesi için ne gereklidir? Techne'nin ilk örnekleri teknik anlamda yazıdır. Yazının gelişim süreci yani çivi yazısından günümüz lazer yazıcılara yolculukta bilim ve teknoloji hiç şüphesiz edebi sanat için önemli bir yardımcıdır. Matbaanın icadı daha çok kitap ve daha fazla bilginin yayılmasına öncülük etmiştir. MS.8.yy da Çin'de basılan ilk ürünler ağaç oyma kalıplar sayesinde olmuştur. Bu baskı türlerine ksilografi (tahta kalıplı baskıcılık sanatı veya blok bask1) denmektedir. (Basalla, 2008:230)

Resim 3. Çin'de Kullanılan İlk Ağaç Baskı Kalıpları Örneği

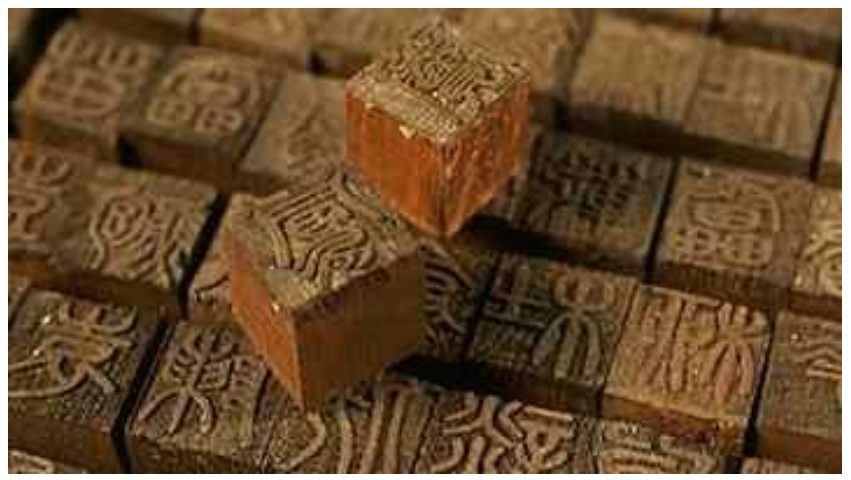

Kaynak: https://io9.gizmodo.com/printed-books-existed-nearly-600-years-before-gutenberg-5910249

Resim 4. 14.Yy Çin Matbaası Örnek İllüstrasyonu.

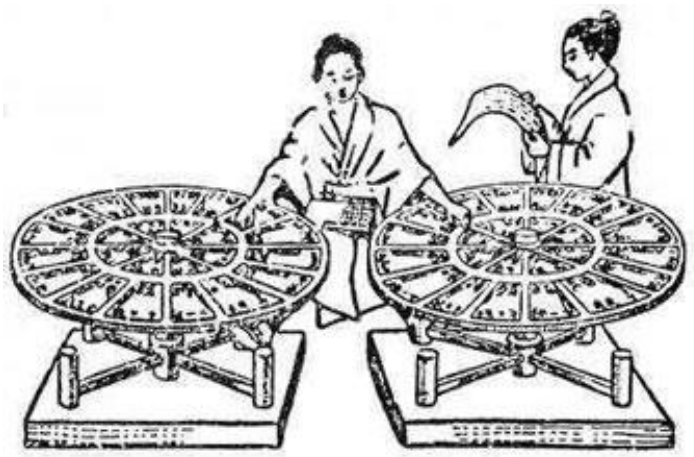

Kaynak: http://www.rtbmatbaa.com/p/ilk-basklar-cin-kaynakl.html

Tahta üzerine kalıpla resim basma sanatının geniş ve yaygın kullanımı sayesinde klasik felsefe ve edebiyat metinleri yeniden basılmış, yazarlar yeni yapıtlar vermeye teşvik edilmiş, kütüphane koleksiyonları sayıca çoğalmış ve genel olarak toplumun okuryazarlığı artmıştır. Sung ${ }^{1}$ dönemine ait 'blok baskılı' kitaplar, Çin kitap-yapımı tarihinde eşsiz bir sanat ve ustalık düzeyini yansıtırlar. Yıllar geçtikçe ağaç oymalar yerlerini 1040 yıllarında Pi Sheng tarafından porselen kalıplara daha sonra da çinko kalıplara bırakmıştır. Aslında dönüşen sadece teknoloji değil sanattır da. 
Avrupa'da kâğıt baskısı matbaanın icadında tam bin yıl sonra kullanılmaya başlanmıştır. 15. yüzyılda Johann Gutenberg'le başlayan metal baskı tekniği yazı karakterlerinin oyulmuş kalıplara boya verilmesiyle birlikte bilginin 1şı̆̆ını yaymaya başlanmıştır. Rönesans'ın aydınlanması bilgi ve okuma, bilinçlenme ve düşünme ortamının oluşmasında matbaanın varlığ 1 yadsınamaz. Matbaa ile birlikte baskı teknikleri gelişmeye devam etmiştir. Metal baskı, litografi gibi teknikler kitap tasarımlarında büyük rol oynamışlardır.

Resim 5. Gutenberg Tarafından Kullanılan Metal Baskı Kalıp Örneği

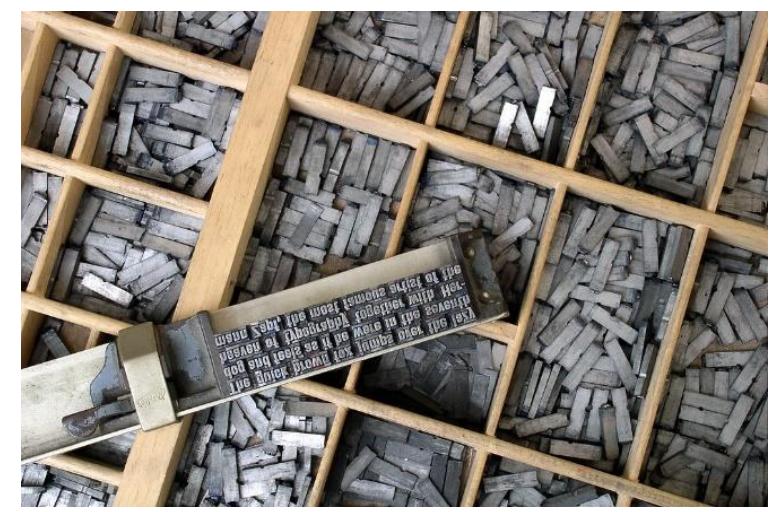

Kaynak: https://robspangler.com/blog/why-im-not-afraid-of-software-or-services-aimed-at-taking-myjob/metal-movable-type-darker/

\section{YENİ TEKNOLOJILERIN SANAT ÜZERINDEKİ ETKISİ}

\subsection{Sanatın teknolojiyi kullanarak kendini göstermesi}

Sanatçılar eserlerini yaratmak için her zaman en ileri malzeme ve teknikleri kullanmışlardır. 15.yy yağlıboya resminde ya da 19.yy fotoğraf çalışmalarında olduğu gibi sanatçılar yeni teknoloji hemen benimsemişlerdir. Kısa bir sürede yeni medyalar geleneksel bir sanat ekipmanı olarak kabul edilmeye başlanmıştır. Dolayısıyla çok açıktır ki sanatın, bilim ve teknolojiden ayrıştırılması sanatçının üretim sürecinde büyük sıkıntılara girmesine neden olacaktır. Çünkü her yeni teknoloji sanatçının yardımcısı ve görev arkadaşıdır. Üretilen her materyal (boya, firça, tuval, heykel ekipmanları, baskı teknolojileri) gibi araç ve gereçler sanatçının yardımcılarıdır. 12.yy boya malzemesiyle 21.yy boya teknolojileri farklıdır. Hem kullanılabilirlik hem de taşınabilirlik açısından farklılık göstermektedir. Döneminde kullanılan her teknoloji ileriki dönemlerde kendini insan ihtiyacına göre değiştirmektedir. Makine ve sanat kavramları beraber düşünüldügünde, teknolojik araçların sanatı kolaylaştırmada ya da istenilen ürünü çıkartmada gerçekçi sonuçlar elde etmeye yardımcı olmaktadır. Örneğin bir hava kompresörüne bağlı hava firçası (Airbrush) ile geniş yüzeyler pürüzsüz ve hızlı bir şekilde boyanabilir. Yumuşak geçişler yapılabilir. Gerçekçilik algısı bir üst seviyeye taşınabilir. Tekniğin olanaklarıyla üretilen eserler makinenin veya teknolojinin izlerini taşımaktadır. Makine ile sanatın bütünlügü böylece korunmuş olmaktadır.

Sanayi devrimiyle beraber ilk otomatik mekiğin icadı makine-zanaat birlikteliğini istemeyenler açısından bir tepkiye neden olmuştur. Bu tepkiyi ateşleyen 1758 yılında Nottinghamlı Ned Ludd adlı bir işçinin yün çorap tezgâhını kırıp parçalamasıyla olmuştur. $\mathrm{Bu}$ ilk makine kırmanın ardından benzer olaylar İngiltere'ye yayılmış, hareket de ilk yıkımı yapan işçinin adı kullanılarak "Luddizm" olarak adlandırılmıştır. Olay o kadar kısa sürede çığırından çıkmıştır ki, yasalara bu suça özel maddeler konmuş, hatta bir süre sonra idam cezası bile getirilmiştir. ama makine kırıcılığının önüne geçilememiştir. Luddistler, fabrikaları hapishane olarak görmekte, ücretli çalışmayı küçümsemekte ve ayrıca zanaatlarının elinden alınacağı düşüncesi hakimdir. İngiltere'de neredeyse 50 yıl sürmüştür. (Linebaugh,2012:13) 
Resim 6. Makine Kırıcılık Dönemini Anlatan Bir Resim

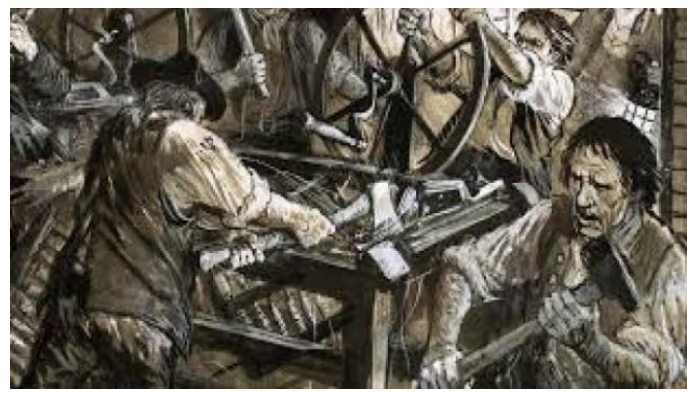

Kaynak: https://ekspreshaberajansi.com/2019/04/30/biraz-vandal-bir-akim-makine-kiricilik/

Sanatın gelişim sürecinde etkisi olan zanaatın makineyle sekteye uğrayacağını düşünen insanlar da bu başkaldırıya sessiz kalmamıştır. 19.yy başlarında sanatın makineden ayrı bir şekilde yol alabileceğini düşünen sanatçılar Arts and Crafts hareketini başlatmışlardır. İngiltere'de başlayan Sanayi Devrimi'nin yarattığı sosyal değişikliklere karşı bir cevap olarak ortaya çıkmıştır. Sanayileşmeye karşı bir tepki olarak ortaya çıkması, sosyalist yapısı ve işçi sınıfını hedefleyen üretim anlayışı şiddete karşı ve barışçıl olan Luddist'ler sanatın makineden ayrılması gerektiğini savunmuştur. Arts and Crafts sanat akımını için ilk belirleyici atılım, Londra'da dünyanın ilk fuarı olan 1851 yılının Büyük Sergisi'dir. Sergideki imalat objelerinin ana eleştirisi, günlük hayat için pek bir faydası olmayan gereksiz süslemelere karşı çıkmak olarak belirtilmiştir. Bu akımda eserler tamamen el işçiliği ya da ona benzer tekniklerle üretiliyordu. Duvar kâğıtlarından mobilya ve süs eşyalarına kadar çeşitli eşyalar tahta kalıplarla ve doğal boyalarla boyanıyordu. Özellikle meşe ağacı, gerçek deri gibi malzemeler kullaniliyordu.

Resim 7. Arts And Craft Ürünü Olan Paul Revere Çömlekçilik, 1910

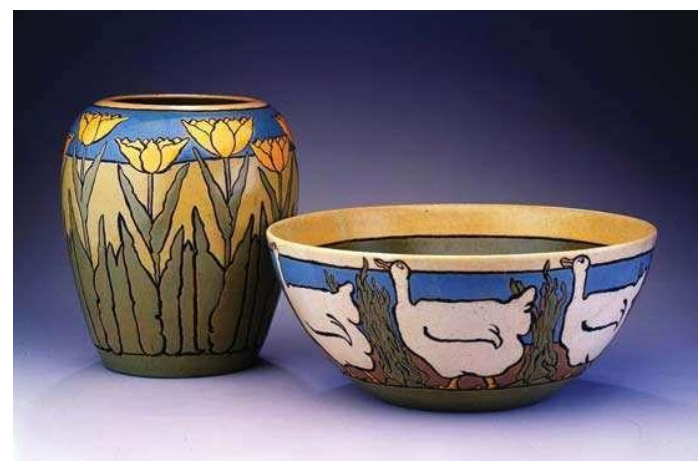

Kaynak: https://www.tasarimakademi.org/arts-and-crafts-sanat-akimi.html

20.yy sanatın bir değişim sürecinde olduğunu gösteren bir dönemdir. Yüzeysel ve durağan sanattan devinim, teknoloji ve makinelerin gözde olduğu bir sanata geçiş dönemidir. Makinelerin varlığ 1 ve sanat bağlamında nerede olduğunu gösteren bir bildiri olarak Fütürist manifesto örnek gösterilebilir.

"Dünyanın güzelliğinin, yeni bir güzellikle daha da zenginleştiğini açıklıyoruz: bu güzellik, hızın güzelliğidir. Karoserini, içine çektiği havanın etkisi ile patlayacakmış görüntüsü veren yılan benzeri boruların süslediği bir yarış arabası motoru işitilirken son derece yüksek bir gurultu çıkaran araba, Samothrakeli Nike'den daha güzeldir.”. (Yılmaz,2010:7) Bu bildirinin ilk sözleri, makinelerin ne kadar önemli birer değer olduğunu gösterir. Sanatın teknolojik gelişmelere yakınlığı açık bir şekilde ilan edilmiştir.

Filippo T. Marinetti tarafindan 1909 yılında yazılan bu bildiriden sonra makine ve insan arasındaki sanatsal bağ kurulmuştur. Fütürist manifesto hayatın her alanında fütürist anlayışı 
yerleştiren düşüncedir. Hızı, dinamizmi ve makineyi adeta kutsayarak sunarlar. Sanatın teknolojik dünyaya muhtaç olduğunu dile getirirler. Sanatı üretirken kullanılan teknoloji sanat eserinin kendisi olmuştur.

Fransız ressam ve heykeltıraş Francis Picabia, ilk sembolik makine sergisini 1915 yılında New York'ta açmıştır. Sergiye sadece üç eseriyle katılmıştır. Fotoğrafçı ve sanat eleştirmeni Paul Haviland, Picabia hakkında 291 adlı sanat dergisinin eylül sayısında kaleme aldığı yazıda şöyle der; "Makine çağında yaşıyoruz. İnsan, makineyi kendi yaptı. Makine hareket için bacaklara, nefes almak için ciğerlere ve atan bir kalbe sahiptir. Sinir sistemini çalıştıran bir elektriği vardır. Gramofon onun sesinin görüntüsüdür. Kamera makinenin gözleridir. Makine annesi olmadan doğan bir kız çocuğudur.” (Camfield,1970:23)

Resim 8. Francis Picabia, aşk komedisi, 1917

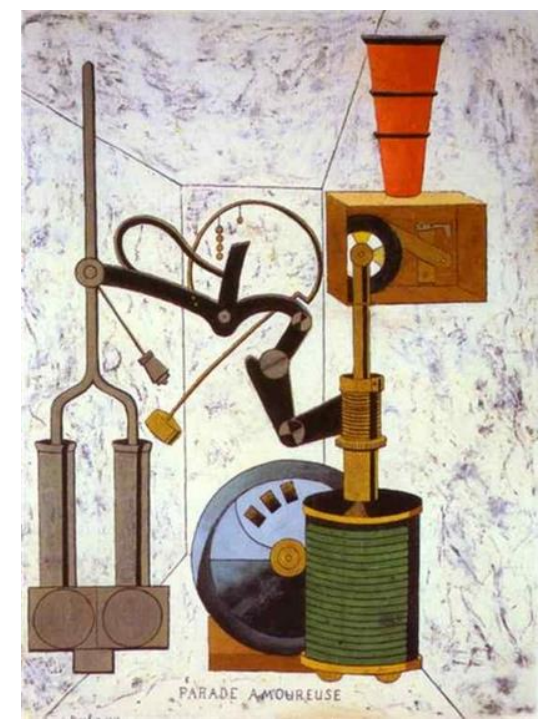

Yirminci yüzyılın başlarında savaş karşıtı ve sanatın geleneksel yönden değişmesi yönündeki manifestosuyla Dada hareketi başlamıştır. Fransız sanatçı Marchel Duchamp'ın 1917 yılında ortaya çıkarttığı hazır nesne (ready-made) kavramı fabrika ürünü nesnelerin sanat bağlamında nereye konacağını göstermiştir. Kavramsal sanat anlayışı ilk ürünlerini teknolojik alt yapısı dayanıklı fabrikasyon ürünlerle vermeye başlamıştır. Pisuarı üreten teknoloji bilmeyerek sanata hizmet etmiştir.

Resim 9. Marcel Duchamp Tarafından Sunulan Çeşme Adlı Çalışması, 1917

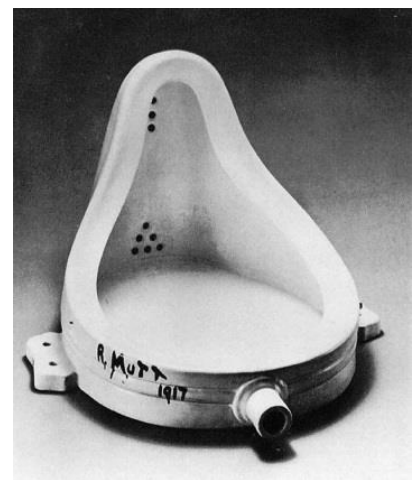

Kaynak: https://kutudasanatvar.com/blogs/kutublog/duchamp-cesme-sanat

Çeşitli malzemelerle hazır nesneleri kullanan Duchamp, farklı malzemeleri bir araya getirerek çalışmalar yapmıştır. Orkide- mantar birlikteliği hazır nesne ve sanat olarak karşımıza çıkmaktadır. Duchamp'ın önemli eserlerinden biri de Büyük Cam adıyla anılan "Bekârları 
Tarafından Çırılçıplak Soyulan Gelin'dir. Marcel Duchamp, eserinde iki ayrılmış bir alan vardır. Marcel Duchamp' ın büyük cam paneller arasında sıkıştırılmış makine parçaları ve farklı objelerden oluşan bir çalışmadır. Duchamp bu eserinde ilk kez retinal art terimini kullanmıştır. Resmin bütününe baktığımızda üst taraf gelin, alt taraf ise damatlar yani erkek bölümüdür. Bir birini tamamlayan bu çalışma erkek bölümünün karmaşası ve mekanik görünümüne karşın yukarının sadeliği göze çarpmaktadır. Orkide ve mantar gibi sanat ve teknoloji birlikteliğini burada kendini göstermektedir. Büyük Cam'ın alt tarafı orkide üst tarafı ise mantar vazifesi görmektedir. Orkidenin yaşam kaynağı mantardır. Ayrılmaz bir birlikteliktir.

Resim 10. Marcel Duchamp, Büyük Cam, Cam üzerine yağlı boya ve kurşun tel,

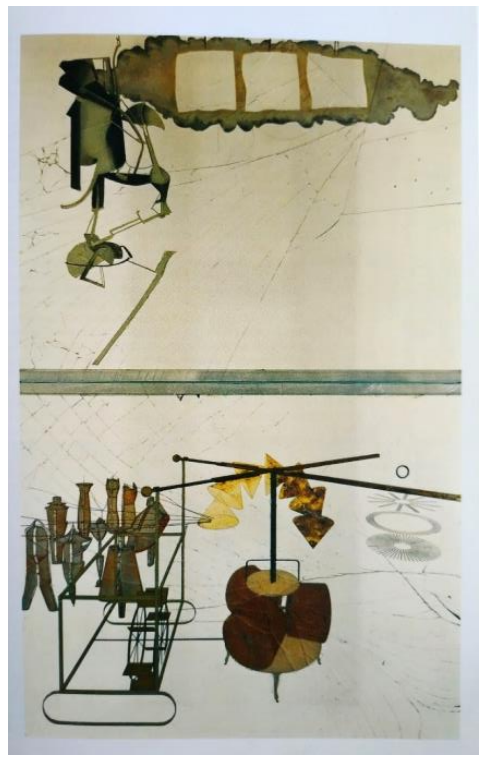

1920'de dönemin Rusya'sında ortaya çıkan bir oluşum olan Konstrüktivizm, çağının malzemelerini heykel ve kabartma alanında kullanarak göstermiştir. Geometrik düzen anlayış1 hâkim olan bu akımda endüstriyel tüm gelişmeleri yüceltmiştir. Metali, plastiği ve camı kullanarak sanatın bir parçası olduğunu ve bu teknolojik yeniliklerin üstünlüğünü göstermiştir. Yapımcı sanat olarak adlandırdığımız bu akım sanatta devrimi amaçlamıştır. Sanatçının bir mühendis ya da bilim adamı olduğunu savunmuşlardır. Toplum ve sanatı birleştirerek makine ve insan bilincini geliştirip yeni bir estetik anlayışın oluşmasına imkân sağlamışlardır. Heykel ve rölyeflerini mekân içinde oluşturmayı hedeflemişlerdir. Resimde geometrik şekiller arasında, heykelde ise makine öğelerinin estetik bir değerle sunmayı amaçlamışlardır.

Resim 11. Vladimir Tatlin, Letatlin,(ahşap,deri,metal), 1931

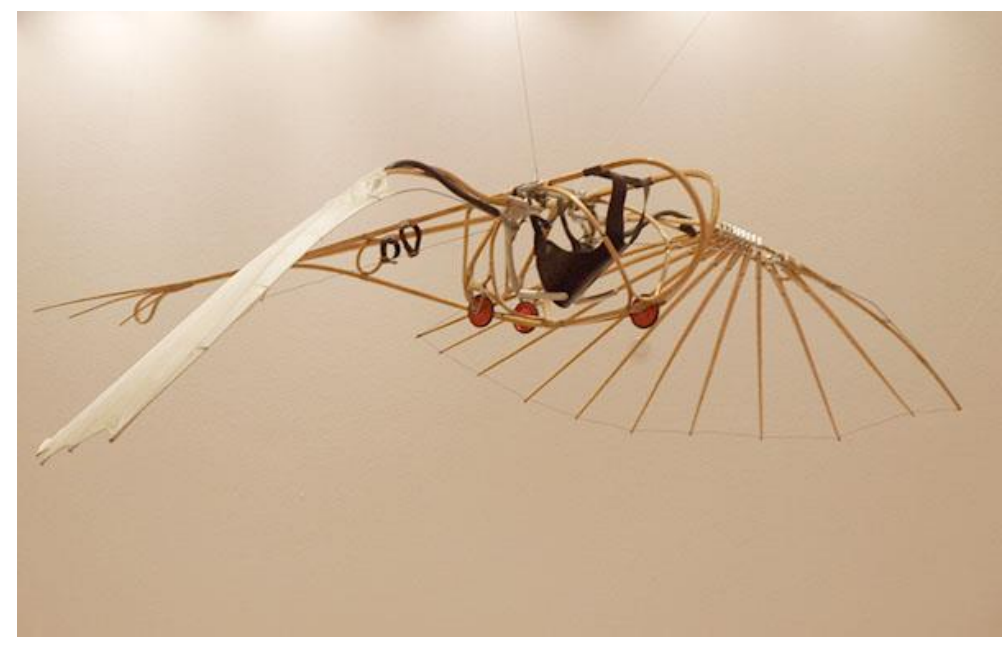


Tatlin 1929-31 yılları arasında insan gücüyle çalışan bir uçak tasarlıyordu. Bu uçağın materyalleri balina kemiği, ipek, tahta gibi malzemeler kullanarak bir araç yaptı. Bu araç içindeki insanın tıpkı bir kuş gibi kollarını ve dirseklerini indirip kaldırarak kanatlarını çırpıyordu.

Geleneksel plastik sanat hareketsizdir. Konstrüktivizm ile başlayan hareket, tekniğin sanatla gösterimi üç boyutlu hali ile sunulmuştur. Zamanda bir anı yakalar ya da ifade eder. Temel olarak bir ışık kaynağı aydınlatmayı sağlamaktadır. Teknoloji ve sanat ilişkisi iki boyutlu yüzeyden veya sabitlikten ayrılarak sesin, 1şığın ve hareketin kullanımıyla yeni bir oluşuma girmiştir. Sanatı teknoloji yardımıyla hareketli gösterme fikri 1930'ların başlarında Amerikalı sanatçı Alexander Calder tarafından Paris ve New York'ta ilk defa sergilendiğinde tanınmaya başland1.

Resim 12. Alexander Calder, Mobile, 1932

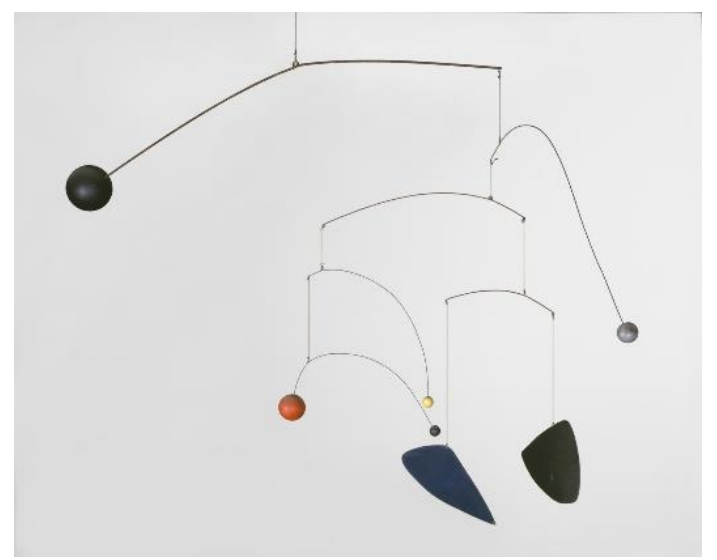

Kaynak: https://www.tate.org.uk/art/artworks/calder-mobile-101686

Çağın getirdiği teknolojik alt yapı yerinde durmayarak ilerlemekteydi. 21.yy' da da hala geçerliliğini koruyan değişim hareketi M.Ö. 500 civarında Efes’te yaşamış düşünür Herakleitos'un sözünü akıllara getirir; "Değişmeyen tek şey, değişimdir” Bunlardan birinin de sanat olduğunu belirtebiliriz. Değişen çağa ayak uydurmak için yeni arayışlara ihtiyaç vardır. 1919 yılında Alman mimar, ressam ve tasarımcı Henry van de Velde ve mimar Walter Gropius tarafından Almanya'nın Weimar şehrinde Bauhaus adında bir okul açılmıştır. Bu eğitim merkezi sanat ve tasarım okulu olarak kurulmuştur. Birinci Dünya Savaşı'ndan sonra kısmen yenilenen dünyaya farklı bir bakış açısı sunan Bauhaus endüstri, sanat ve zanaat birleşmesini teknolojik altyapı sunarak göstermeye çalışmıştır. Bu üç birleşimin sağlanması ile en etkili ve en güçlü tasarımların yapılacağını savunan Bauhaus, çalışmalarını da bu yönde ilerletmeye başlamıştır. Bu sayede de Bauhaus modernist çizgisi de oluşmaya başlamıştır. 1919 ile 1928 yılları arasında Walter Gropius Bauhaus'un yöneticiliğini yapmıştır. Gropious'a göre çok daha fonksiyonel, kalıcı ve ucuz ürünlerin üretilmiş olduğu bir stil yaratılmalıdır. Bu da Bauhaus ile mümkündür. (Stokstad,2011:1055) Bauhaus ile teknik kullanılarak sanatla yoğrulmuş bir stil elde etmişlerdir. 
Resim 13. Bauhaus Sergi Posteri (1923)

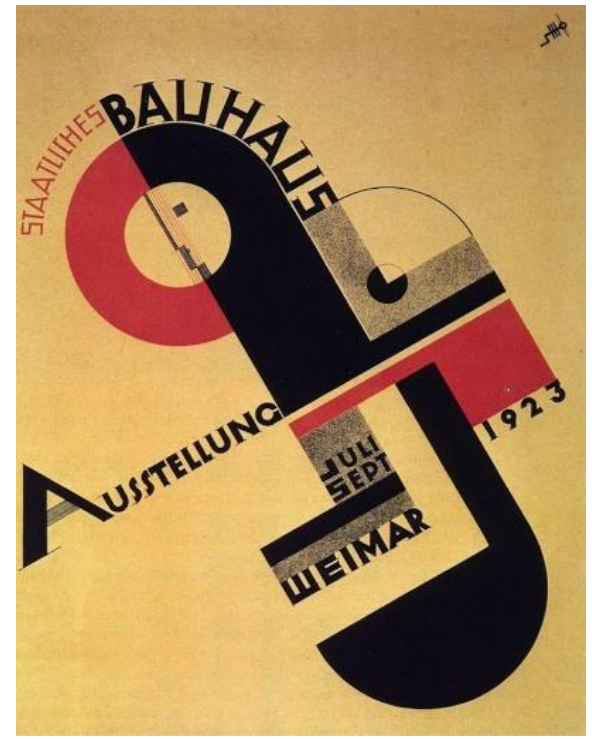

Kaynak: http://www.tasarimakademi.org/bauhaus-sanat-akimi.html

19.yy da fotoğraf makinesi icat edildiğinde sanatçılar yeni teknolojiye temkinli bir duruş sergilemiştir. Sanatının elinden alınacağı fotoğrafa mesafe koymuş, hatta bu yeni tekniği ve malzemeyi düşman olarak görmüştür. Zamanla fotoğraf makinesinden daha gerçekçi çalışmalar yapan hiperrealist ressamlar, bu görüntü makinesinden faydalanmaya başlamışlardır. Tıpkı orkidenin bir mantardan faydalanarak gelişip büyümesi, değişip dönüşmesi gibidir.

Joseph Nicephore Niepce tarafından 1814 yılında çekilen ilk fotoğraf, sanat dalının bir parçası olabilmesi için uzun mücadeleler verecektir. Teknoloji ve sanat bazen kan uyuşmazlığ yaşamaktadır. Bu gibi durumların yani tekniğin sanat içinde kullanımı, her ikisini beraber bütünleştirmede zamana ihtiyaç olduğu görülmektedir. (Yaykın, 2010:35) Tekniğin olanaklarıyla yeniden üretim mantığı fotoğraf makinesinde kendini gösterir. Her sanat eseri yeniden üretilebilir ancak biricikliğini sorgular (Benjamin, 1993:45) Üretilen sanat eserinin biricikliği onun eşsiz oluşundan kaynaklanmaktadır. Teknolojinin sanat adına sanatçıya destek olması hiç şüphesiz kolaya kaçma değil teknikten faydalanmadır. Bunlardan biri de camera obscuradır. Camera obscura, her tarafı tamamen kapalı, içine rahatça bir insanın girebileceği büyüklükte karanlık; yalnızca bir yüzeyinin ortasında, ışığın geçmesini sağlayan bir deliği bulunan oda olarak da tanımlanabilir. Çevreden yansıyan 1şıklar delikten geçmektedir ve odanın içindeki yüzeyde bir görüntü oluşturmaktadır. İleriki yüzyıllarda teknoloji bu ilkel alete önce mercek daha sonra anı yakalayan kimyasal bileşenlerle yolculuğuna yön verecektir.

Vedat Nedim Tör bir sergi açılışında fotoğraf hakkında şunları söylemiştir; "Fotoğrafla güzel sanatlar arasındaki çarpışma devam ediyor. Güzel sanatlar fotoğrafı aralarına almamak için ne kadar ısrara ederse etsin, fotoğraf o guruba girmek için elinden geleni yapıyor. $\mathrm{Bu}$ tecrübeler gösteriyor ki o, kendi teknik malzemesine esir kaldıkça âdi zanaat, bu malzemeyi insan idrakinin emrinde kullandıkça güzel sanattır.”(Köroğlu,2004:2) 
Resim 14. 1814 Yılında Çekilen İlk Fotoğraf

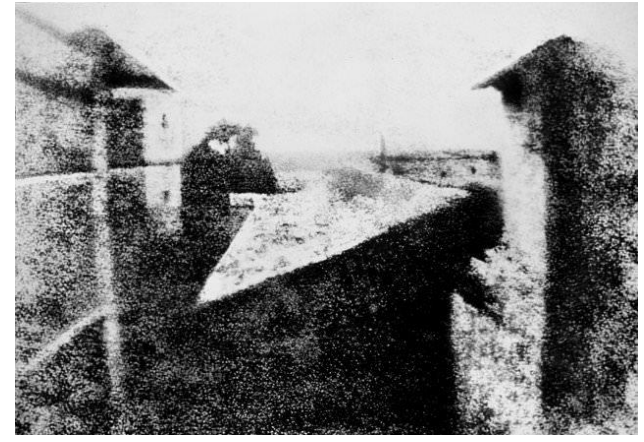

Kaynak: http://www.senbildiye.com/herseyin-bir-sonu-oldugu-gibi-bir-ilki-de-vardir-iste-dunyanin-ilkleri/

Sanatın her alanında kullanılan teknoloji günümüz post modern dünyasında artık bir adım öteye giderek düşünen makineler ile insan arasında köprü kurmaktadır. Tekniğin sanat bağlamında sayısal veri olarak yani bir ve sıfırlardan oluşan bedenlerle vücut bulması çağın getirdiği sonuçlardır. Tiyatro, sinema, edebiyat, plastik sanatlar gibi farklı disiplinlerde yapay zekâ yardımıyla sanat örnekleri gerçekleştirilmektedir. Tiyatroda kullanılan teknolojik alt yapı izleyene daha gerçekçi, sahneler arası geçişlerde hız ve zaman tasarrufu sağlarken insan bedeninin makine ile birlikteliğini göstermektedir.15.yy Rönesans döneminde teknolojimakine birlikteliği Leonardo da Vinci'ye de ilham kaynağı olmuştur. Sahne tasarımlarını hareketli ve izleyenleri duygu olarak oyunun içinde olmasını sağlamaya çalışmıştır. Leonardo da Vinci'nin sahne tasarımı mitolojik bir öykü olan Orfe adında bir kahramanın hikayelerini anlatan bir tiyatro oyunudur. Sahne hareketli olarak tasarlanmıştır. Döneminin teknolojik açıdan en gelişmiş sahne tasarımı olarak tanımlanmaktadır. (Pirrotta ve Povoledo, 1982, 39)

Resim 15. Orfe Adlı Oyunun Sahne Tasarımı (Yeniden Üretim)

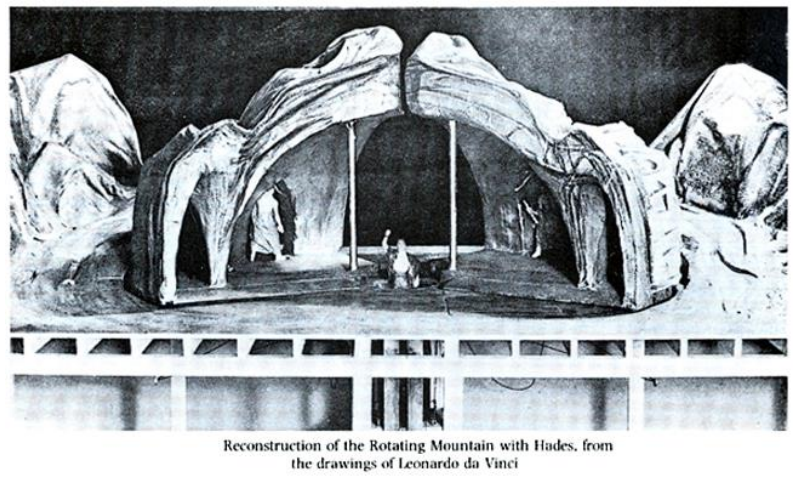

Kaynak:http://www.estherlederberg.com/EImages/Extracurricular/Renaissance+Baroque/Perspective \%20Theatres/Stage\%20Machinery\%20Leonardo\%20da\%20Vinci.html

Sahnede bulunan her bir dekor makine-insan bağının teknoloji olarak yansımasını göstermektedir. Bazı sanat üreten kişilerin tıpkı 19.yy’daki makine kırıcılık dönemindeki gibi bu teknolojik gelişmelerin sanatı bitireceğini savunmuşlardır. Sanatçının yapay zekâ ile mücadelesi, fotoğraf makinesiyle olan tanışmasına benzemektedir. Yapay zekânın resim yapması bir ressamın resim yapmasını ya da bir heykeltıraşın heykel yapmasını engellemez.

Rönesans'tan itibaren gösteri sanatlarının izleyiciyi etkilemesi ve görsel açıdan çeşitlilik göstermesi televizyon teknolojisinin evlere girmesini ve benimsenmesini kolaylaştırmıştır. İnsanlar devasa boyuttaki sahneleri küçük bir kutudan izleme firsatı bulmuşlardır. 1960'larla birlikte televizyonun iletişim aygıtı olarak kullanılması sanatçıların dikkatini çekmiştir. Bir sanat nesnesi olarak kullanılmasının önünü açmıştır. Televizyon teknolojisinin 1960'lar ile birlikte video sanat dalında örnekler verilmeye başlanmıştır. Pop art dönemi ile kitle iletişim 
teknolojisi olan televizyonun sanat ürünü olarak sunulması dijital medyanın önünü açmıştır. Televizyonun toplumu bilinç olarak uyuşturması, sanatçıların teknoloji ile teknolojiyi eleştirme yöntemine başvurmalarını sağlamıştır. Video sanatının öncüsü Fluxus sanatçısı Nam June Paik' dir. Televizyon ekranlarını bir düzenek ile birleştiren sanatçı, yığın halinde çoklu ekranları sergileyerek video yerleştirmeler gerçekleştirmiştir. Video sanatının günümüzde de benimsenip yayılmasının nedenlerinden biri de kolay ulaşılabilir ve yayımlanabilir oluşudur.

Resim 16. Nam June Paik Tarafindan Yapılan Andy Warhol Robotu, 1994

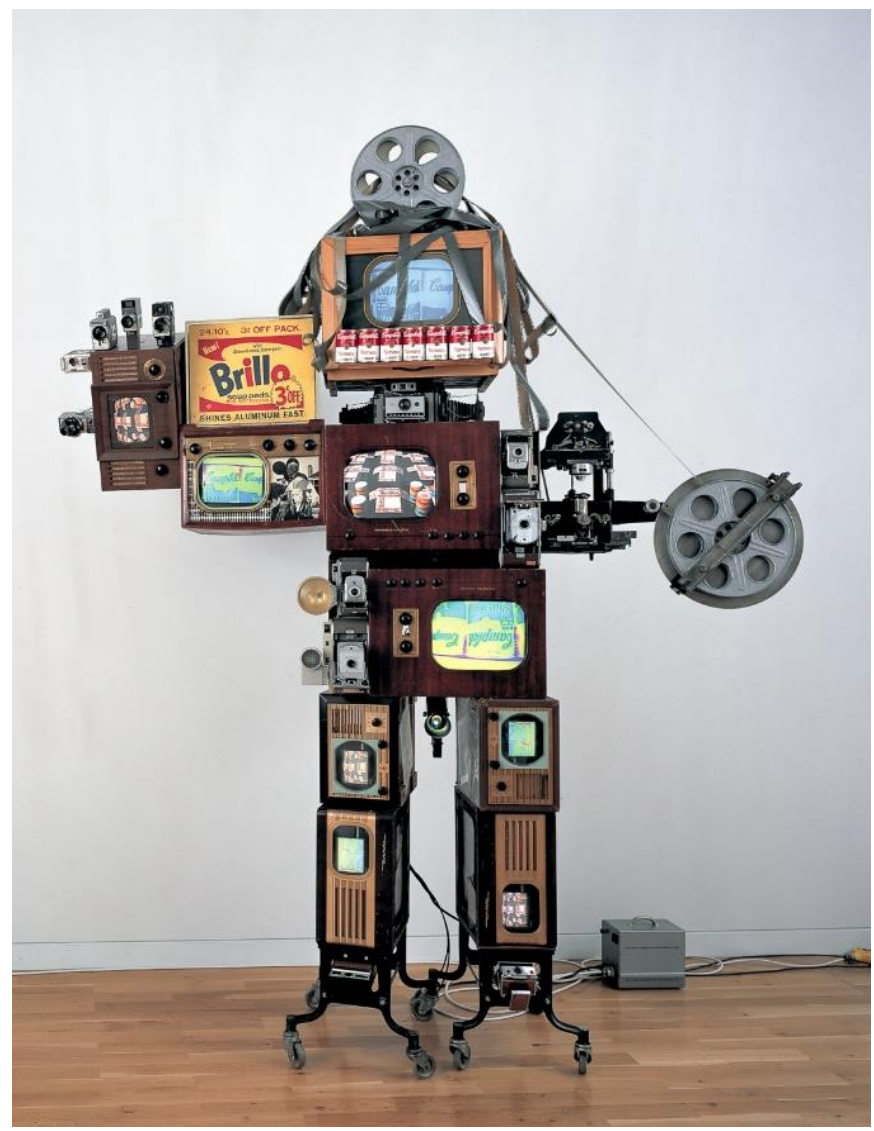

Kaynak: https://www.kunstmuseum-wolfsburg.de/collection/nam-june-paik/andy-warhol-robot-en-us/

1960'larda elektronik medyanın adımları atılırken transistör olarak adlandırılan elektronik devre elemanı Kanada' da 22 Ekim 1925 tarihinde Avusturya-Macaristanlı bir fizikçi olan Julius Edgar Lilienfeld tarafından icat edilmişti. Transistörün icadı ile elektrik ile elektronik arasında ince hat ayrılmıştır. Analog siyah beyaz ekranlar (CRT) yerini renkli televizyonlara dönüştürmekteydi. 20. yüzyılda transistörün icadı ile elektronik medyanın özellikle de sibernetik ve yapay zekâ örneklerinin yavaş yavaş kendini gösterdiği bir dönemdir. 1956 da Fransız Sibernetik sanatçısı Nicolas Schoffer, sibernetik sanatın ilk örneklerinden biri olan CYSP-1'i üretmiştir. Philips firması mühendisleri ile beraber çalışan sanatçı, robot bilim ve etkileşimli ortam gibi kinetik sanat eserleri vermiştir. Bilgisayar ile sanat ve kinetiği birleştiren sanatçı ilk büyük bilgisayar sergisi olan "digital visions:Computersand Art" ile Amerika birleşik devletlerin de dolaşmıştır. (Shanken, 2012: 62) 
Resim 17. Nicolas Schoffer'ın 1956 Yılında Yaptığı CYSP-1 Adlı Çalışma

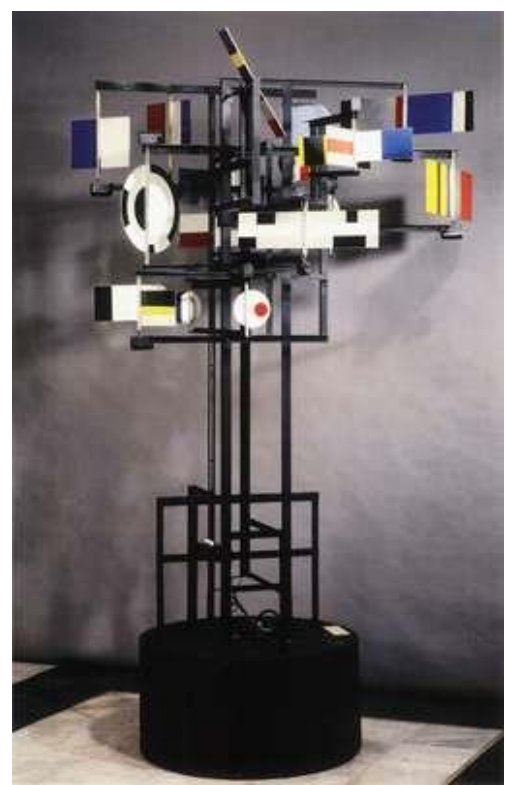

Kaynak: http://dada.compart-bremen.de/item/agent/472

Bilgisayar sanatı CAD/CAM yazılımlarının yani bilgisayar destekli tasarım ürünlerinin üretilmesine olanak sağlamıştır. 1975-6 yıllarında bilgisayar desteğiyle yapılan ilk tasarım Utah Çaydanlığı adlı çalışmadır. Bu çalışma 3 boyutlu tasarımın mimari, mühendislik ve endüstri tasarım alanlarında kullanılmaya başlanmıştır. 1980'lerde kişisel bilgisayarların yaygınlaşması bireysel çalışmaların özellikle de sanatçıların ürünlerini evinde tasarlamalarına olanak sağlamıştır.

Resim 18. Martin Edward Newel, Utah Çaydanlığı, 1975

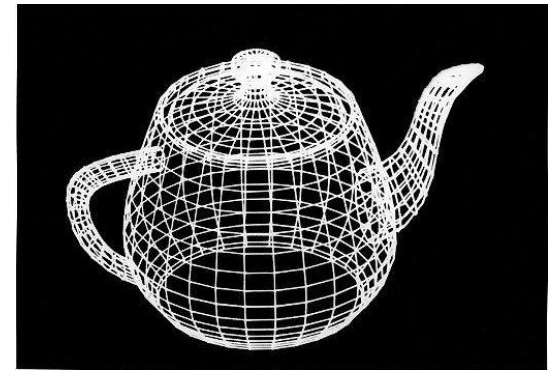

2000'lerle bilgisayar sistemleri gelişmiştir. Sanatçılar hızlı prototiplendirme denilen şekillendirme ve tasarım tekniğiyle 3D yazıcılarla eserlerini üretmişlerdir. Sonraki dönemlerde Palm(avuç içi) bilgisayarlar ve tablet bilgisayarlar devreye girerek hızlı prototip kavramını bir adım öteye taşıyacaklardır İngiliz ressam David Hockney, çalışmalarını iPad, iPhone ve bilgisayar gibi dijital ortamlarda hazırlayan sanatçı, fotokopi, faks ve inkjet baskı makinesi gibi yeni medya ürünleriyle sunmaktadır. 
Resim 19. David Hockney İpad Çizimi. 2011.

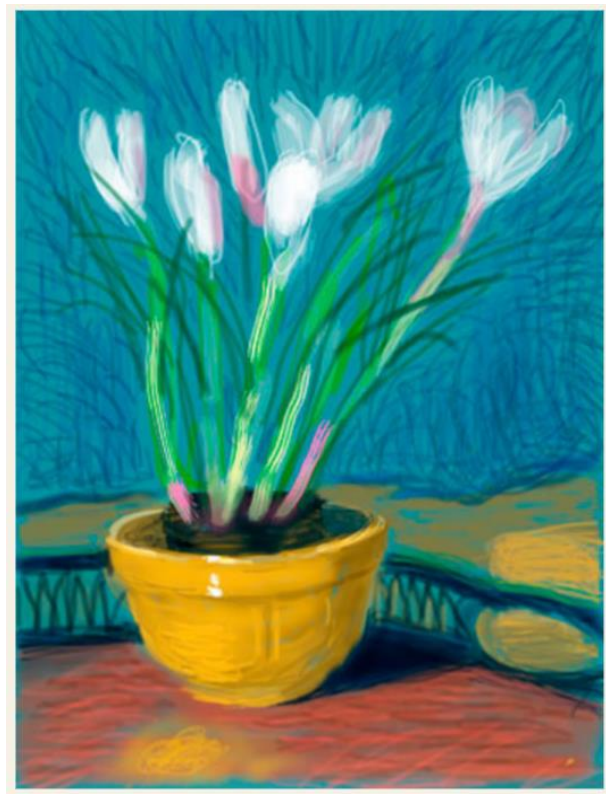

1990’da Rus sanatçı Bulat M. Galeyev tarafından yapılan Elektronik Painter, Rus sanat kolektifinin televizyon ve video sanatına duyduğu ilginin artışının ilk ürünü olarak görülmektedir. Elektronik jeneratörler, canlı renklerden soyut görüntüler çıkaran renkli televizyon resim tüplerinin monitörlerinin üzerine konmuştur. Bilgisayar programı komutlarına dayanan bu figürler senkronize ses eşliğinde zaman içinde değişime uğramaktadır.

Resim 20. Elektronik Painter, 1990

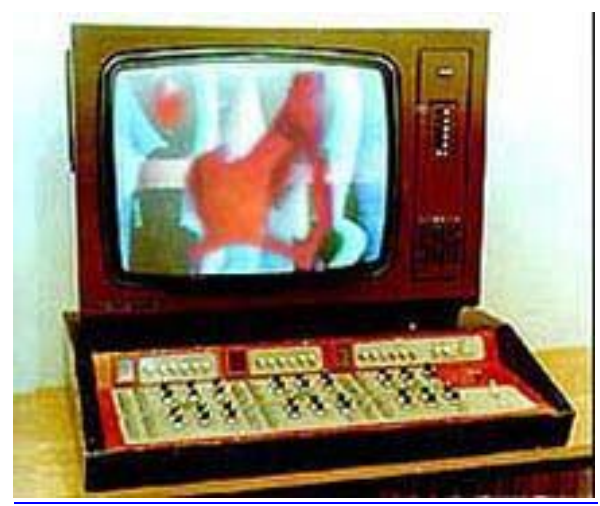

Kaynak: https://prometheus.kai.ru/el_e.htm

Sanatçının bilgisayarla ürettiği eserler, yapıldığı andan itibaren yaşayan bir form haline gelmektedir. Kendini güncelleyen, kendi başına hareket eden bir formdur. Sanatçının vazifesi hayalet orkidenin yaşamını sürdürmesi için gerekli besini (mantarı) yani teknolojiyi sanat ürününe vermesidir.

Bilgisayarın devreye girmesi ile kodlu sistemlerin yani algoritmik sayısal değerlerin 1 ve 0'lardan oluşan sayısal dünya, sanat üzerinde etkisini sürdürmektedir. 2006 yılında sanatçılar Max Dean, Rafaello D'andrea ve Matt Donovan tarafindan üretilen "Robotic Chair" isimli çalışma bilgisayar görme sistemleri, robot cihazlar, yapay zekâ yazılımı ve mekanik sistemler kullanılmıştır. Yapılan bu çalışma kendi kendine dağılıp birleşen bir sistemden oluşmaktadır. Sandalye ahşaptan yapılmıştır. Klasik bir sandalye görüntüsündedir. Fakat içerdiği teknoloji sandalyeyi işlevinden çıkarmıştır. Düşünen ve ne yapması gerektiğini belirleyen bu sandalye, bir döngü içinde işlemini sürdürmektedir. (Shanken, 2012: 164) 
Resim 21. Kendi kendine dağılıp birleşen sandalye

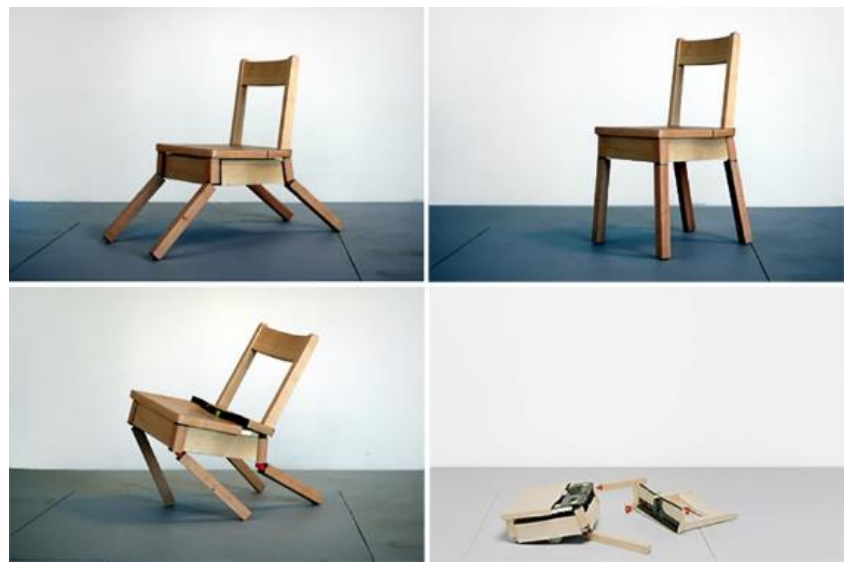

Kaynak: https://www.designboom.com/technology/robotic-chair-edit-toronto-raffaello-d-andrea-maxdean-matt-donovan-09-24-2017/attachment/robotic-chair-edit-toronto-max-dean-matt-donovanraffaello-dandrea-designboom-02/

1990'larda internetin her eve girmesi tıpkı kişisel bilgisayarların evlere girmesi kadar önemliydi. İletişim açısından dünyanın küçülmesi ile ülkeler arası mesajlaşma olanağının sunulması sanat için ayrı bir anlam taşımaktaydı. Yapılan eserlerin diğer sanatçılar yada izleyenlere hızlı bir şekilde internet olan her yerden erişime açık olması gösterilebilir. Sanatçılar zaman ilerledikçe yani teknolojik altyapının gelişimiyle sadece eserlerini göndermek için interneti kullanmadılar. İnternet artık bir sanat eserine dönüşmüştür. $\quad$ http://geogoo.net adlı internet sitesi, 2008 yılında Yeni Medya (New Media) olarak tanıtılmıştır. Hollandalı sanatçılar Joan Heemskerk ve Dirk Paesmans tarafindan tasarlanan web sitesi, izleyenlere interaktif bir uygulama olanağı sağlamaktadır. "GEO GOO" adındaki bu çalışma Google Map yazılımının kodlarını kullanır. İnternet sitesinde kullanıcıların algoritma yardımıyla seçebilecekleri koordinatlarla Google Map uygulamasında bulunan simgeleri istedikleri veri girişiyle kontrol etmektedirler. Orkidenin yani sanatın modern besleyicisi digital mantar olmuştur.

Resim 22. http://geogoo.net

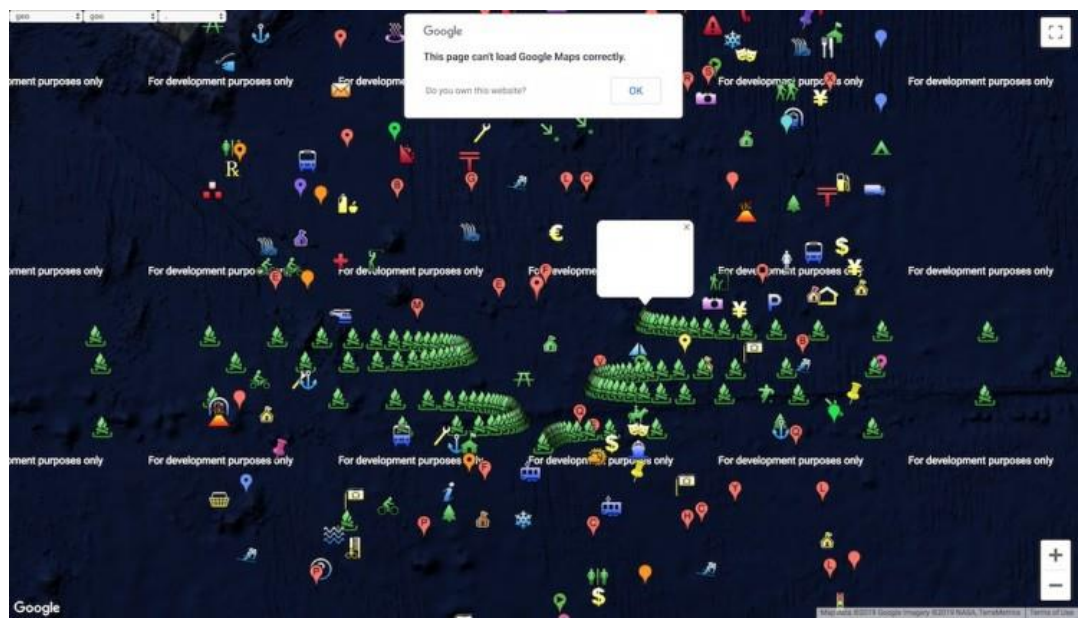

Kaynak: http://artonetwentynine.blogspot.com/2011/04/jodi-geo-goo-2008.html 


\section{SONUÇ}

Sanat-Teknoloji ve Hayalet Orkide-Mantar birlikteliği et ile tırnak gibidir. Sanayi devriminden itibaren buharlı makineler endüstri sahnesine çıkmış, insan hayatını kolaylaştıran dost metal bedenlere dönüşmüştür. Elektriğin icadı ile icat edilen tüm makineler yeniden gelişim sürecine girmiştir. 19.yy tüm zamanların en çok icat çıkaran, teknolojinin geliştiği bir dönem olmuştur (Freyer, 2014: 10) Doğa, bir çiçeğin büyümesine, gelişmesine yardım eden bir mantarın aşkı ile beraberliğini sürdürmektedir. Hayalet orkidenin yaşaması için mantar, sanatın ilerlemesi için teknolojiye ihtiyaç vardır. Bu bir çıkar ilişkisi değildir. Ne sanat teknolojisiz, ne de teknoloji sanatsız kalabilir. Tekno-sanat, dijital ortama yönelmektedir. Geçmişin geleneksel sanatı gibi plastik sanatlar dahi bu ilerleme karşısında kendini yenileyerek çağa ayak uydurmaktadır. Sanat ve teknoloji insan eliyle bu birlikteliği körüklemektedir. Sanat ve teknoloji artık ayrılmaz bir bütün olarak görülmektedir. Kullanılan en ufak bir gelişme sanat adına büyük işlerin üretilmesine vesile olmuştur. İnsan-makine-sanat ile üç sac ayağı ile birliktedir. Teknolojiyi sanattan koparmak, sanatın ömrünü kısaltarak sıradanlaşma sürecine girmesine neden olacaktır. Kendi kendine resim yapan şiir yazan makineler, kendinden düşünen süper zekalı robot kollar var olacaktır ve daha da gelişecektir. Ama bu makinelerin başında insan muhakkak bulunacaktır. İnsan duygu denilen o içsel ifade biçimini makinelere vermeyecektir. En üstün, kusursuz bir sanat eseri üretme çabası sanatçının kaygısıdır. En iyiyi ve en güzeli arama çabası sanatçının beslenme kaynağıdır. Geçmişte yaşanılan makine karşıtlı̆̆ gibi bir dönem ileriki yüzyıllarda karşımıza çıkar mı bilinmez ama şimdiden yapay zekanın ilerleyişinden rahatsız olan bir topluluk vardır. İnsan, makine olmadan üretemez, makine de insan olmadan çalışamaz. İnsanlığın ilk gününden son gününe kadar makineler var olacaktır. Teknoloji ve sanat karmaşık sistemlerde vücut bulacaktır. Kablolar, elektrik motorları, sayısal devreler, led ekranlar ve yapay zekâ sanatı sinir ağları gibi kapsamıştır. Ama kontrol hep insanda olacaktır. 


\section{KAYNAKÇA}

\section{Kitaplar:}

BASALLA, George, (2008), Teknolojinin Evrimi, Cem Soydemir, Tübitak, Ankara

BENJAMIN, Walter, (1993), Pasajlar, Çev. Ahmet Cemal, Yapı Kredi yayınları, İstanbul

FREYER, Hans, (2014), Sanayi Çağı, Bedia Akarsu- Hüseyin Batuhan, Doğu Batı Yayınları, İstanbul

HEIDEGGER, Martin, (2017), Heidegger: Teknoloji ve İnsanlığın Geleceği, Çev.Ahmet Aydoğan, Say Yayınları, İstanbul

İPŞİROĞLU, Nazan-Mazhar, (2009) Sanatta Devrim, Hayalbaz Kitabevi, İstanbul

LINEBAUGH, Peter, (2012), Makine Kırıcılık, Deniz Esen, Otonom Yayıncılık, İstanbul

RAUNIG, Gerald, (2012), Bin Makine Toplumsal Hareket Olarak Makinenin Kisa Felsefesi

Çev. Münevver Çelik, Otonom Yayıncılık, İstanbul

SHANKEN, Edward A., (2012), Sanat ve Elektronik Medya, Çev. Osman Akınhay, Agora Kitaplığ 1 , İstanbul

YAYKIN, Murat, (2010), Sanat, Teknoloji, Bilim ve Fotoğraf, Kalkedon Yayıncılık, İstanbul

\section{İnternet Kaynakları:}

EKSPRES HABER AJANSI, 2019, Biraz vandal bir akım: Makine Kırıcılık, [online] https://ekspreshaberajansi.com/2019/04/30/biraz-vandal-bir-akim-makine-kiricilik/ [Erişim Tarihi: 6.4.2019]

ENCYCLOPAEDIA BRITANNICA, WARREN Lynne, Alexander Calder [online] https://www.britannica.com/biography/Alexander-Calder [Erişim Tarihi: 5.3.2018]

FIRST NATURE, DAVIES, Paul Harcourt, 2016, Epipogium aphyllum - Ghost Orchid, [online] https://www.first-nature.com/flowers/epipogium-aphyllum.php [Erişim Tarihi: 2.6.2019]

FİLOZOF.NET, 2019, Henry Van De Velde Kimdir? [online] http://www.filozof.net/Turkce/edebi-sahsiyetler-kisilikler-biyografileri/17402--henryvan-de-velde-kimdir-hayati-eserleri-hakkinda-bilgi.html [Erişim Tarihi: 4.7.2019]

GRAHAM, R. A. (1953). Epipogium aphyllum Sw. in Buckinghamshire. Watsonia 3: 33 [online] http://archive.bsbi.org.uk/Wats3p33.pdf [Erişim Tarihi: 4.2.2019]

NEWITZ, Annalee, 2012, Printed books existed nearly 600 years before Gutenberg's Bible [online] https://io9.gizmodo.com/printed-books-existed-nearly-600-years-beforegutenberg-5910249 [Erişim Tarihi: 6.5.2018]

ROBOTISTAN, İZGÖL, Kerem, 2017, Transistör Nedir? Ne İşe Yarar? Transistör Çeşitleri https://maker.robotistan.com/transistor-nedir/ [Erişim Tarihi: 10.5.2019]

TASARIM AKADEMI, 2018, Arts And Crafts Sanat Akımı, [online] https://www.tasarimakademi.org/arts-and-crafts-sanat-akimi.html [Erişim Tarihi: 1.7.2019]

TATE ONLINE, 2008, Alexander Calder [online] https://www.tate.org.uk/art/artworks/caldermobile-101686 [Erişim Tarihi: 1.2.2019] 
THE EUROPEAN JOURNAL OF ENVIRONMENTAL SCIENCES, 2011, Fragrance composition of Dendrophylax lindenii (Orchidaceae) using a novel technique applied in situ [online] http://web.natur.cuni.cz/uzp/ejes/index.php/ejes/article/view/61 [Erişim Tarihi: 1.6.2019]

\section{NOTLAR}

${ }^{1}$ M.S.8. yy'da Hou Zhou hanedanının bir generali olan Çov Kuangyin tarafından kurulan hanedanlık. 